\title{
Article \\ Molecular Signature of Small Cell Lung Cancer after Treatment Failure: The MCM Complex as Therapeutic Target
}

\author{
Shunsuke Misono ${ }^{1}\left(\mathbb{D}\right.$, Keiko Mizuno $^{1}$, Takayuki Suetsugu ${ }^{1}$, Kengo Tanigawa ${ }^{1}{ }^{\circledR}$, Nijiro Nohata $^{2}(\mathbb{D}$, \\ Akifumi Uchida ${ }^{1} \mathbb{D}$, Hiroki Sanada ${ }^{1}$, Reona Okada ${ }^{3}$, Shogo Moriya ${ }^{4}$, Hiromasa Inoue ${ }^{1}$ (D) and Naohiko Seki ${ }^{3, *(D)}$ \\ 1 Department of Pulmonary Medicine, Graduate School of Medical and Dental Sciences, Kagoshima University, \\ Kagoshima 890-8520, Japan; k8574402@kadai.jp (S.M.); keim@m.kufm.kagoshima-u.ac.jp (K.M.); \\ taka3741@m2.kufm.kagoshima-u.ac.jp (T.S.); k8802984@kadai.jp (K.T.); \\ akiuchi@m3.kufm.kagoshima-u.ac.jp (A.U.); k8173956@kadai.jp (H.S.); \\ inoue@m2.kufm.kagoshima-u.ac.jp (H.I.) \\ 2 Merck Sharp and Dohme (MSD) K.K., Tokyo 102-8667, Japan; nijiro.nohata@merck.com \\ 3 Department of Functional Genomics, Chiba University Graduate School of Medicine, Chuo-ku, \\ Chiba 260-8670, Japan; reonaokada@chiba-u.jp \\ 4 Department of Biochemistry and Genetics, Chiba University Graduate School of Medicine, Chuo-ku, \\ Chiba 260-8670, Japan; moriya.shogo@chiba-u.jp \\ * Correspondence: naoseki@faculty.chiba-u.jp; Tel.: +81-43-226-2971
}

\section{check for} updates

Citation: Misono, S.; Mizuno, K.; Suetsugu, T.; Tanigawa, K.; Nohata, N.; Uchida, A.; Sanada, H.; Okada, R.; Moriya, S.; Inoue, H.; et al. Molecular Signature of Small Cell Lung Cancer after Treatment Failure: The MCM Complex as Therapeutic Target. Cancers 2021, 13, 1187. https:// doi.org/10.3390/cancers13061187

Academic Editors: Noriaki Sunaga and Massimo Barberis

Received: 21 December 2020

Accepted: 3 March 2021

Published: 10 March 2021

Publisher's Note: MDPI stays neutral with regard to jurisdictional claims in published maps and institutional affiliations.

Copyright: (c) 2021 by the authors. Licensee MDPI, Basel, Switzerland. This article is an open access article distributed under the terms and conditions of the Creative Commons Attribution (CC BY) license (https:// creativecommons.org/licenses/by/ $4.0 /)$.
Simple Summary: Small cell lung cancer (SCLC) is a fatal malignant tumor with a poor prognosis for patients who relapse after first-line treatment. There are few effective treatments for SCLC patients with relapse. Elucidation of the molecular network related to treatment resistance is an important issue for this disease. In this study, the molecular signature of SCLC specimens after treatment failure was generated. Several pathways, e.g., "cell cycle", "homologous recombination", "DNA replication", and "p53 signaling" were identified as the enriched pathways in this signature. Aberrant expression of MCM2, MCM4, MCM6, and MCM7 were detected in SCLC clinical specimens after treatment failure. This signature contains molecules involved in treatment resistance and will contribute to the study of SCLC molecular pathogenesis.

Abstract: Small cell lung cancer (SCLC) is a highly aggressive cancer, and patients who become refractory to first-line treatment have a poor prognosis. The development of effective treatment regimens is urgently needed. In this study, we identified a gene expression signature of SCLC after treatment failure using SCLC clinical specimens (GEO accession number: GSE162102). A total of 1,136 genes were significantly upregulated in SCLC tissues. These upregulated genes were subjected to KEGG pathway analysis, and "cell cycle", "Fanconi anemia", "alcoholism", "systemic lupus erythematosus", "oocyte meiosis", "homologous recombination", "DNA replication", and "p53 signaling" were identified as the enriched pathways among the genes. We focused on the cell cycle pathway and investigated the clinical significance of four genes associated with this pathway: minichromosome maintenance (MCM) 2, MCM4, MCM6, and MCM7. The overexpression of these $M C M$ genes was confirmed in SCLC clinical specimens. Knockdown assays using siRNAs targeting each of these four MCM genes showed significant attenuation of cancer cell proliferation. Moreover, siRNA-mediated knockdown of each MCM gene enhanced the cisplatin sensitivity of SCLC cells. Our SCLC molecular signature based on SCLC clinical specimens after treatment failure will provide useful information to identify novel molecular targets for this disease.

Keywords: small cell lung cancer; cell cycle pathway; MCM2; MCM4; MCM6; MCM7

\section{Introduction}

Lung cancer is the one of the most malignant cancers, with high morbidity and mortality rates (approximately 2,100,000 people were diagnosed, and 1,800,000 patients died 
worldwide in 2018) [1]. Lung cancer is divided into two subtypes based on histological classification: small cell lung cancer (SCLC) and non-small lung cell cancer [2]. Approximately $15 \%$ of lung cancer patients are diagnosed with SCLC, and due to rapid progression and strong invasiveness of SCLC tumors, approximately $70 \%$ of patients with SCLC have metastasis (extensive disease (ED)-SCLC) by the time of diagnosis [3].

Platinum-based chemotherapy is used as the initial treatment for patients with EDSCLC, and it has improved survival [4]. A clinical feature of SCLC is that it responds efficiently to treatment initially but then acquire drug resistance during treatment $[5,6]$. There are few effective treatments for ED-SCLC patients with relapse, who rarely survive beyond 2 years (range 7-10 months) [7]. Clarifying the molecular mechanism by which cancer cells acquire drug resistance is an important issue for this disease.

SCLC is rarely treated surgically and obtaining tumor samples suitable for genomebased studies is especially difficult for ED-SCLC. Regardless, several genome-based studies have been conducted so far to elucidate the malignant phenotype of SCLC cells $[8,9]$. In recent studies, expression data deposited in the Gene Expression Omnibus (GEO) database were downloaded and reanalysed for differentially expressed genes and pathways in SCLC tissues [10-12]. For example, one of those studies merged four GEO datasets (GSE60052, GSE43346, GSE15240, and GSE6044) and identified 20 SCLC-related genes (S1PR1, MAD2L1, CDKN2A, STIL, NDC80, NCAPG, PAD51AP1, TTK, PRM2, EZH2, PRC1, UBE2C, RFC4, CENPF, TCP2A, HMGB3, TYMS, SOX4, MCM2, and SMC4) [10].

Several previous studies have performed whole genome analyses using SCLC clinical specimens [13-19]. It has been reported that SCLC has high mutation rates and genomic instability cause to tobacco carcinogens $[15,20]$. The tumor-suppressor genes TP53 and RB1 are the most frequently mutated genes in SCLC [13-16,18]. A meta-analysis of four studies reporting high-throughput sequencing data for SCLC revealed that $R B 1$ plays a pivotal role in tumor progression and the subsequent mutation burden of SCLC [19]. Those highthroughput sequencing studies revealed that several mutated genes are strongly involved in SCLC carcinogenesis (e.g., SOX2, FGFR1, LRP1B, KIAA1211, and PTEN) [13,14,16,17]. Moreover, mutations have been identified in several genes involved in the PI3K/AKT / mTOR pathway (e.g., PIK3CA, PTEN, AKT, RICTOR, and $m$ TOR) in SCLC [15]. A large-scale cohort study of SCLC revealed that the presence of genetic alterations in the PI3K/AKT/mTOR pathway are strongly associated with poor survival of patients with ED-SCLC [18]. Those studies suggested that activation of PI3K/AKT/mTOR-mediated signaling enhances SCLC tumorigenesis, and that the involved genes are promising therapeutic targets for SCLC.

In this study, we identified a SCLC expression signature using clinical specimens obtained from SCLC patients after treatment failure. Normal tissues, primary lesions, and metastatic lesions were collected from three patients (autopsy specimens), and comprehensive gene expression analyses were performed. Our mRNA expression signature data was deposited in the GEO (Gene Expression Omnibus: GSE 162102) database and is accessible.

To discover genes involved in the aggressive nature and drug resistance of SCLC cells, we focused on genes that are highly expressed in cancer cells. The highly expressed genes were found to be enriched in "cell cycle", "Fanconi anemia", "alcoholism", "systemic lupus erythematosus", "oocyte meiosis", "homologous recombination", "DNA replication", and "p53 signaling" pathways. Next, we performed functional analyses focusing on four minichromosome maintenance (MCM) genes (MCM2, MCM4, MCM6, and MCM7), which are involved in the cell cycle and cell replication. The replisome is a complex molecular machinery that are essential for DNA replication and are therapeutic target for human cancers. The MCM-family are major component proteins of DNA replisome [21]. The aberrant expression of these MCM genes contributed to an aggressive nature in SCLC cells. Furthermore, siRNA-mediated knockdown of $M C M$ genes enhanced the cisplatin sensitivity of SCLC cells. There have been few reports of gene expression profile in treatment failure of SCLC clinical specimens. This signature contains molecules involved in treatment resistance and will contribute to the study of SCLC molecular pathogenesis. 


\section{Materials and Methods}

\subsection{Collection of SCLC Autopsy Specimens and Cell Lines}

In this study, all SCLC and normal lung tissue specimens were obtained from three patients who died of drug-resistant SCLC with metastatic lesions at Sendai Medical Association Hospital in 2018. SCLC cell lines H82 and SBC-3 were purchased from the American Type Culture Collection (Manassas, VA, USA) and the Japanese Cancer Research Resources Bank (Osaka, Japan), respectively.

\subsection{Immunohistochemistry and Western Blot Analysis}

Immunostaining was performed with a VECTASTAIN ${ }^{\circledR}$ Universal Elite ABC Kit (catalog no.: PK-6200; Vector Laboratories, Burlingame, CA, USA) using SCLC tissues obtained by autopsy. The expression of synaptophysin, chromogranin A and MCM family members (MCM2, MCM4, MCM6 and MCM7) in normal lung tissue was obtained from the Human Protein Atlas (version 20.0; http:/ / www.proteinatlas.org/ (accessed on 5 February 2021)). In western blotting, cell lysates were prepared using a RIPA buffer (catalog no.: sc-24948, Santa Cruz Biotechnology Inc., Dallas, TX, USA). A total of $20 \mu \mathrm{g}$ protein was separated on SuperSep ${ }^{\mathrm{TM}}$ Ace $(7.5 \%, 13$ well) (FUJIFILM Wako Pure Chemical Corporation, Osaka, Japan) and transferred onto polyvinylidene fluoride membranes (catalog no.: PPVH00010, Merck KGaA, Darmstadt, Germany). The procedures have been described previously [22-25]. The primary antibodies used are shown in Table S1.

\subsection{Identification of the mRNA Expression Signature for Treatment Failure of SCLC}

In this study, we extracted total RNA from SCLC autopsy specimens and evaluated gene expression using Agilent SurePrint G3 Human GE v3 8x60K microarrays. The raw microarray data were registered in GEO (GSE 162102). Our selection strategy is presented in Figure S1.

\subsection{Transfection of siRNAs into SCLC Cells and Functional Assays}

The cell proliferation assay was determined by XTT assays using a Cell Proliferation Kit (Biological Industries, Beit-Haemek, Israel). In the cell cycle assay, SCLC cells were treated with BD Cycletest ${ }^{\mathrm{TM}}$ Plus DNA Reagent Kit (BD Biosciences, Franklin Lakes, NJ, USA) according to the manufacturer's protocol. Apoptotic cells were detected using a PE Active Caspase-3 Apoptosis Kit (BD Biosciences). These SCLC cells were analyzed using a flow cytometer (BD FACSCelesta ${ }^{\mathrm{TM}}$ Flow Cytometer, BD Biosciences). BD FACSDiva Software (version 8.0.1.1, BD Biosciences) was used to examine the flow cytometry data. The procedures used for transfecting siRNAs and for the functional assays (cell proliferation, cell cycle and apoptosis) were described in our previous studies [22-25]. The reagents used are listed in Table S1.

\subsection{RNA Preparation and Quantitative Reverse-Transcription Polymerase Chain Reaction (qRT-PCR)}

The methods used for RNA extraction from clinical specimens and cell lines and for qRT-PCR have been described previously [22-25]. In brief, the isolation of total RNA from clinical specimens was performed using TRI reagent (Cosmo Bio Co., Ltd., Tokyo, Japan) and total RNA of cell lines was extracted by Isogen II (NIPPON GENE Co., Ltd., Tokyo, Japan) according to the manufacturer's instructions. The quantification and quality of total RNA were checked by NanoDrop 2000c spectrophotometer (Thermo Fisher Scientific Inc., Waltham, MA, USA). cDNA was synthesized using PrimeScript ${ }^{\mathrm{TM}}$ RT Master Mix (catalog no.: RR036A, Takara Bio Inc., Shiga, Japan). Subsequently, we evaluated the expression of the gene by TaqMan Real-Time PCR Assays. qRT-PCR reactions were run using the StepOnePlus Real-Time PCR System (Applied Biosystems, Foster City, CA, USA). TaqMan probes and primers are shown in Table S1. 


\subsection{Combined Treatment Effect on Cell Viability}

To determine the effect of cisplatin combined with MCM2, MCM4, MCM6, or MCM7 knockdown on cisplatin sensitivity, SCLC cell lines were seeded at 4000/well in a 96-well plate. The following day, cisplatin $(0.001,0.01,0.1,0.5,1,2,5,10,25$, or $100 \mu \mathrm{M})$ was administered for $72 \mathrm{~h}$ with or without transfection of the MCM-targeting siRNAs. Cell viability was assessed by XTT assay, and the $\mathrm{IC}_{50}$ of cisplatin was determined.

\subsection{Statistical Analyses}

Statistical analyses were performed using GraphPad Prism 7 (GraphPad Software, La Jolla, CA, USA) and JMP Pro 14 (SAS Institute Inc., Cary, NC, USA). One-way analysis of variance (ANOVA) and Tukey's post-hoc test were used for multiple group comparisons.

\section{Results}

\subsection{Clinical Course of SCLC Patients and Immunostaining of Autopsy Tissues}

In this study, we obtained autopsy specimens from three patients who died of drugresistant metastatic SCLC. The characteristics of the patients and their clinical specimens are shown in Tables 1 and 2. The clinical courses of the patients are presented in Figure 1A-C.

To confirm the histological type, the autopsy specimens were stained with hematoxylin and eosin and subjected to immunostaining of synaptophysin, chromogranin A, and CD56, which are specific markers of neuroendocrine tumors including SCLC (Figure 2).

A

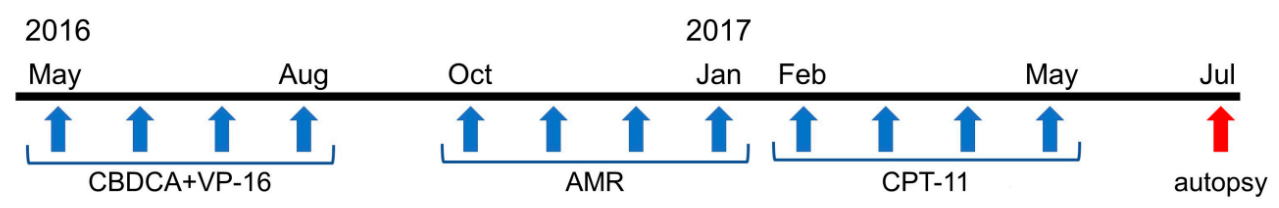
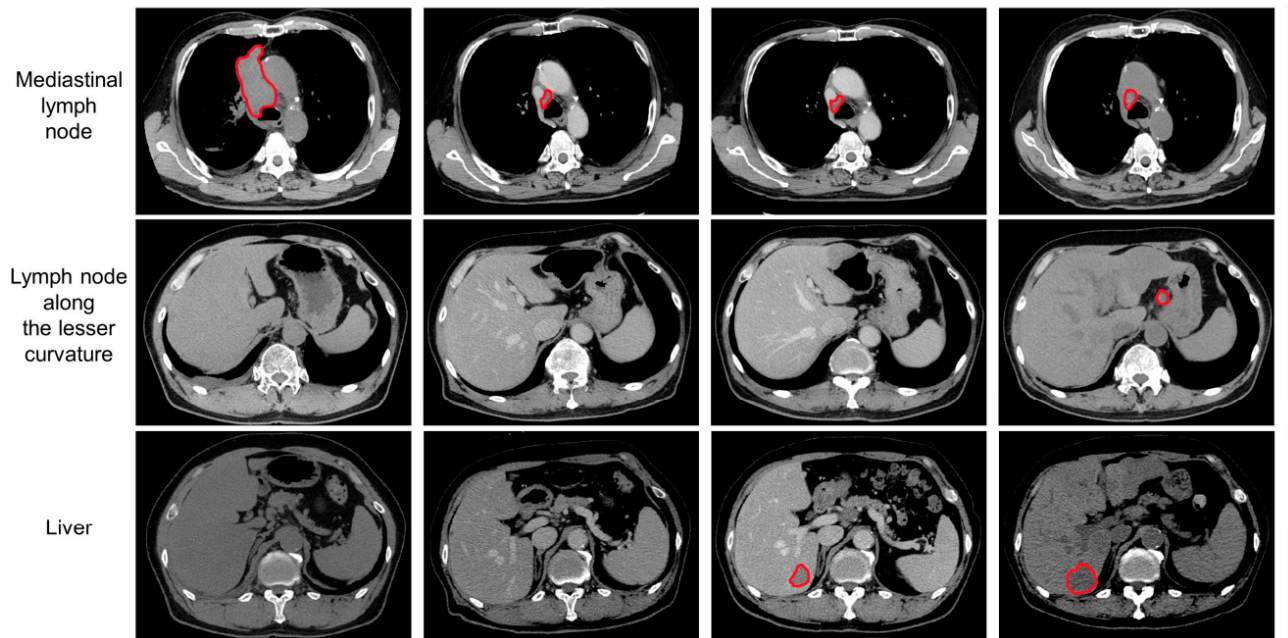

Figure 1. Cont. 
B

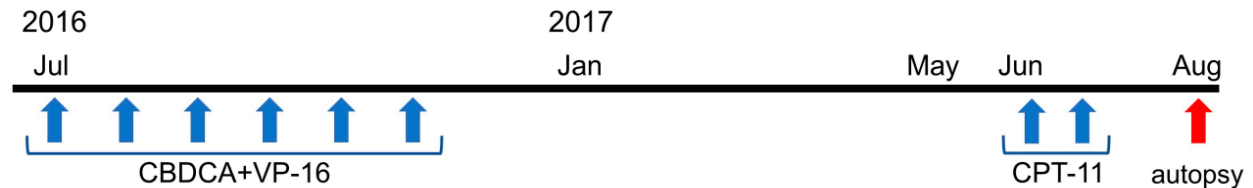
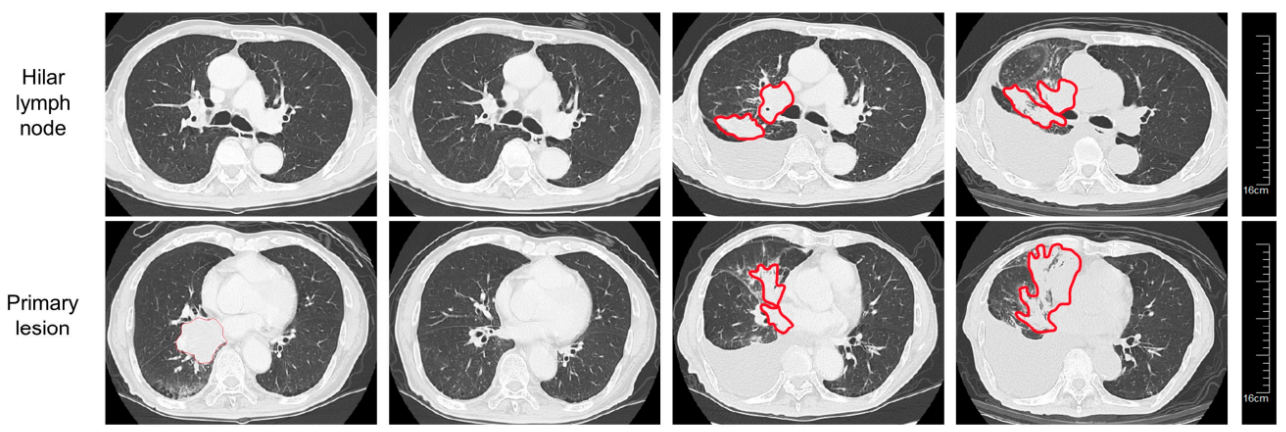

2017
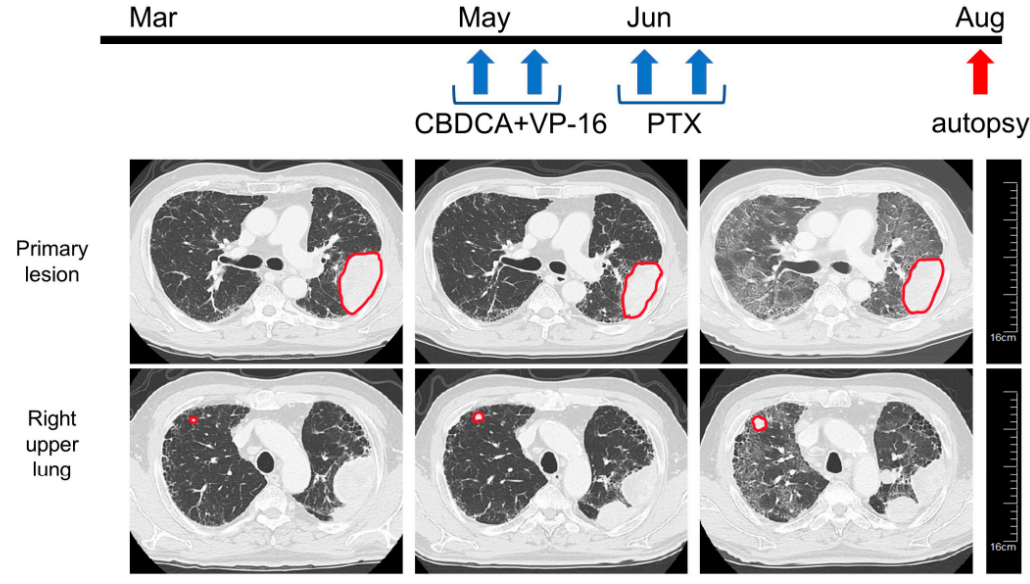

Figure 1. Clinical courses of the three patients with small cell lung cancer (SCLC). (A) The clinical course of case no. 1. A 66-year-old Japanese man visited due to facial edema and dyspnea in May 2016. Chest-abdomen computed tomography (CT) revealed a tumor located from the right hilum to the mediastinum, compression of the superior vena cava, and bone metastasis at the seventh lumbar vertebra. The patient was diagnosed with SCLC by sputum cytology. First-line chemotherapy with carboplatin (CBDCA) and etoposide (VP-16) was initiated, resulting in a partial response after four cycles. However, in October 2016, CT showed a new liver metastasis. Following four cycles of second-line chemotherapy with amrubicin (AMR), the patient underwent four cycles of third-line chemotherapy with irinotecan (CPT-11), but further disease progression occurred. In July 2017, the patient died, and autopsy was performed. We obtained tissue samples from the metastases in the mediastinal lymph node, lesser curvature lymph node, liver, and para-aortic lymph node. (B) The clinical course of case no. 2. A 77-year-old Japanese man presented to our hospital with fever in May 2016. CT identified a mass located from the right hilum to the lower lobe of the right lung. Bronchoscopic biopsy of the lung mass revealed SCLC, and fluorodeoxyglucose-positron emission tomography revealed multiple bone metastases. He underwent six cycles of first-line chemotherapy with CBDCA and VP-16 and experienced a partial response. At 6 months after discontinuation of chemotherapy, CT showed an increase in size of the tumor in the right lower lobe, as well as a malignant pleural effusion. Thus, second-line chemotherapy with CPT-11 was started, but further disease progression occurred. In August 2017, the patient died, and autopsy was performed. We obtained tissue samples from the tumors in the right lower lobe (primary lesion) and the right hilar lymph node metastasis. (C) Clinical course of case no. 3. A 65-year-old Japanese man had experienced coughing for 2 months before visiting our hospital in April 2017. CT revealed a mass in the upper lobe of the left lung, lymphadenopathy in the left hilum and mediastinum, and multiple nodules in the right lung. Bronchoscopy with transbronchial biopsy confirmed a diagnosis of SCLC. First-line chemotherapy with CBDCA and VP-16 was initiated, but the intrapulmonary metastases in the right upper lobe increased in size. A switch to second-line chemotherapy with paclitaxel had no effect. In August 2017, the patient died, and autopsy was performed. We obtained tissues from the tumors in the left upper lobe (primary lesion) and the right intrapulmonary metastases. 
Table 1. Clinical features of the SCLC patients.

\begin{tabular}{|c|c|c|c|c|c|c|c|c|c|}
\hline No. & Sex & Age & BI & $\mathbf{T}$ & $\mathbf{N}$ & $\mathbf{M}$ & Stage & Therapy & Remarks \\
\hline 1 & $\mathrm{M}$ & 67 & 1440 & 4 & 2 & $1 \mathrm{~b}$ & IV & $\begin{array}{l}\text { Platinum based } \\
\text { chemotherapy }\end{array}$ & $\begin{array}{l}\text { Microarray expression analysis } \\
\text { IHC staining }\end{array}$ \\
\hline 2 & $\mathrm{M}$ & 78 & 1180 & $2 b$ & 2 & $1 \mathrm{~b}$ & IV & $\begin{array}{l}\text { Platinum based } \\
\text { chemotherapy }\end{array}$ & $\begin{array}{l}\text { Microarray expression analysis } \\
\text { IHC staining }\end{array}$ \\
\hline 3 & $\mathrm{M}$ & 65 & 990 & $2 a$ & 3 & $1 \mathrm{a}$ & IV & $\begin{array}{l}\text { Platinum based } \\
\text { chemotherapy }\end{array}$ & $\begin{array}{l}\text { Microarray expression analysis } \\
\text { IHC staining }\end{array}$ \\
\hline
\end{tabular}

IHC: immunohistochemistry, BI: Brinkman index.

Table 2. Site of sample collection for microarray expression analysis.

\begin{tabular}{ccc}
\hline A. Cancer Tissues & $n=8$ & Case No. \\
\hline Sample Name & Tissue & 2 \\
\hline SCLC-Pri-1 & Primary lesion & 3 \\
SCLC-Pri-2 & Primary lesion & 1 \\
SCLC-Meta-1 & Lesser curvature lymph node metastasis & 1 \\
SCLC-Meta-2 & Mediastinal lymph node metastasis & 1 \\
SCLC-Meta-3 & Para-aortic lymph node metastasis & 2 \\
SCLC-Meta-4 & Right hilar lymph node metastasis & 1 \\
SCLC-Meta-5 & Liver metastasis & 3 \\
SCLC-Meta-6 & Right intrapulmonary metastasis & \\
B. Normal lung tissues & Tissue & case no. \\
\hline Sample name & Normal lung tissue & 1 \\
\hline SCLC N-1 & Normal lung tissue & 1 \\
SCLC N-2 & Normal lung tissue & 2 \\
SCLC N-3 & Normal lung tissue & 3 \\
\hline SCLC N-4 & &
\end{tabular}

A HE stain
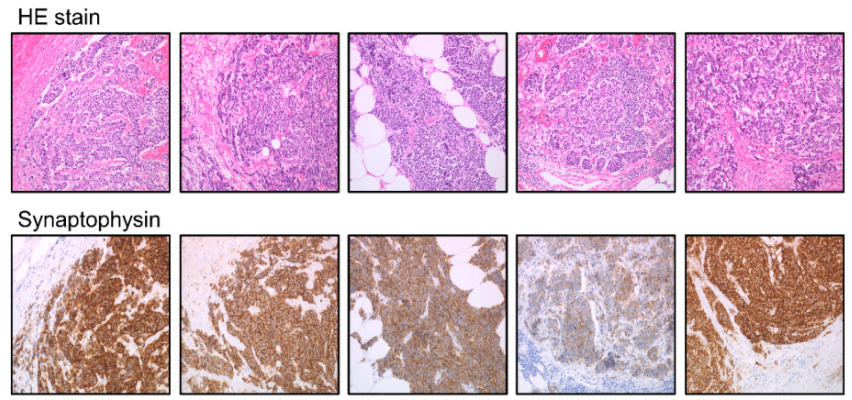

Chromogranin A

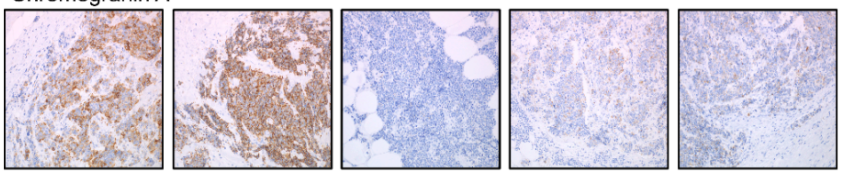

CD56
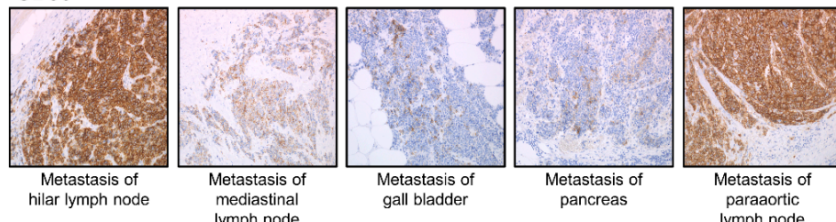

Figure 2. Cont. 
B

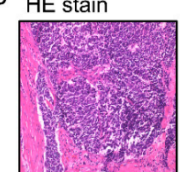

Synaptophysin

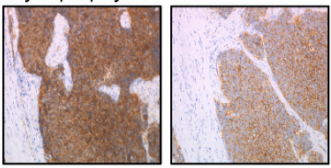

Chromogranin A

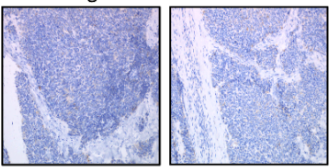

CD56

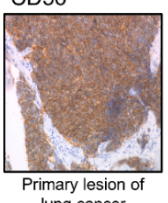

Primary lesion of
lung cancer

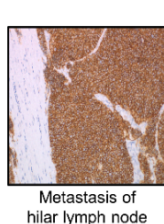

C HE stain

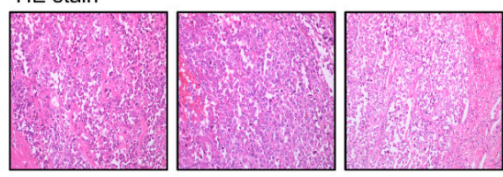

Synaptophysin

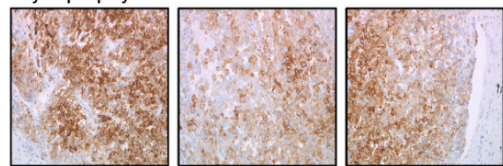

Chromogranin A

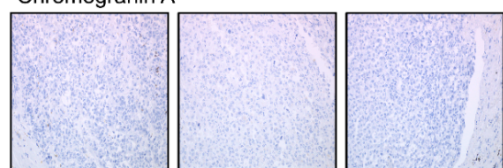

CD56
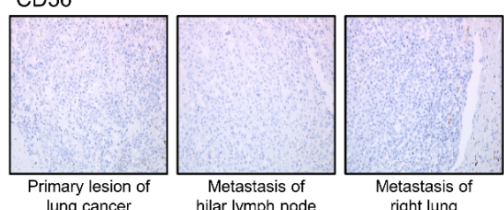

Figure 2. Histopathological findings in the three SCLC patients (A) case no. 1, (B) case no. 2, and (C) case no. 3. Micrographs were taken at $200 \times$ magnification.

\section{2. mRNA Expression Signature of SCLC after Treatment Failure}

Using Agilent SurePrint G3 Human GE v3 $8 \times 60 \mathrm{~K}$ microarrays, the gene expression signature of SCLC after treatment failure was determined. Among the genes differentially expressed between the cancer and normal lung tissues, a total of 1136 genes upregulated in the cancer tissues (Log fold change $>2$ ) were extracted. Subsequently, KEGG pathway analysis was performed using the GeneCodis program (https:/ /genecodis.genyo.es / (accessed on 4 December 2020)), revealing that these genes are associated with the following pathways, "cell cycle", "Fanconi anemia", "alcoholism", "systemic lupus erythematosus", "oocyte meiosis", "homologous recombination", "DNA replication", and "p53 signaling" (Table 3 and Tables S2-S4). The microarray data were deposited in the GEO database (accession number: GSE162102).

Table 3. Significantly enriched annotations of the upregulated genes identified by microarray expression analysis of SCLC clinical specimens.

\begin{tabular}{ccc}
\hline No. of Genes & $p$-Value & Annotations \\
\hline 28 & $2.28 \times 10^{-12}$ & (KEGG) 04110: Cell cycle \\
15 & $9.66 \times 10^{-8}$ & (KEGG) 03460: Fanconi anemia pathway \\
26 & $6.19 \times 10^{-7}$ & $($ KEGG) 05034: Alcoholism \\
21 & $2.12 \times 10^{-6}$ & (KEGG) 05322: Systemic lupus erythematosus \\
18 & $7.67 \times 10^{-5}$ & $($ KEGG) 04114: Oocyte meiosis \\
10 & $8.54 \times 10^{-5}$ & (KEGG) 03440: Homologous recombination \\
9 & $1.92 \times 10^{-4}$ & (KEGG) 03030: DNA replication \\
10 & $1.21 \times 10^{-2}$ & (KEGG) 04115: p53 signaling pathway \\
\hline
\end{tabular}

\subsection{Expression of MCM2, MCM4, MCM6, MCM7 in SCLC Tissues}

Of the upregulated genes identified in SCLC tissues, we focused on MCM family genes (MCM2, MCM4, MCM6, and MCM7), which are involved in the cell cycle pathway (Table 4).

We confirmed by immunohistochemistry that the expression of MCM2, MCM4, MCM6, and MCM7 was significantly upregulated in SCLC specimens compared with normal tissues (case no. 1-3) (Figure 3 and Figures S2-S4). 
Table 4. Upregulated genes associated with the cell cycle pathway.

\begin{tabular}{|c|c|c|c|c|c|c|c|}
\hline \multirow[b]{2}{*}{$\begin{array}{c}\text { Entrez } \\
\text { GeneID }\end{array}$} & \multirow[b]{2}{*}{$\begin{array}{c}\text { Gene } \\
\text { Symbol }\end{array}$} & \multirow[b]{2}{*}{ Gene Name } & \multirow[b]{2}{*}{ Location } & \multicolumn{4}{|c|}{ Normalized Read Count $\left(\log _{2}\right)$} \\
\hline & & & & $\begin{array}{c}\log _{2} \\
\text { Fold } \\
\text { Change }\end{array}$ & $\begin{array}{c}\text { Normal } \\
\text { Lung } \\
\text { Tissues }\end{array}$ & $\begin{array}{c}\text { SCLC } \\
\text { Tissues }\end{array}$ & $\begin{array}{c}p- \\
\text { Value }\end{array}$ \\
\hline 7272 & TTK & TTK protein kinase & $6 q 14.1$ & 3.67 & -0.37 & 3.30 & 0.0034 \\
\hline 9134 & CCNE2 & cyclin E2 & $8 \mathrm{q} 22.1$ & 3.57 & 0.05 & 3.62 & 0.0002 \\
\hline 4173 & MCM4 & minichromosome maintenance complex component 4 & $8 q 11.21$ & 3.33 & 0.20 & 3.54 & 0.0004 \\
\hline 699 & BUB1 & budding uninhibited by benzimidazoles 1 homolog & $2 q 13$ & 3.18 & -0.25 & 2.92 & 0.0040 \\
\hline 701 & $B U B 1 B$ & budding uninhibited by benzimidazoles 1 homolog beta & $15 q 15.1$ & 3.08 & -0.03 & 3.05 & 0.0018 \\
\hline 9133 & CCNB2 & cyclin B2 & $15 q 22.2$ & 3.05 & 0.05 & 3.10 & 0.0055 \\
\hline 1029 & CDKN2A & cyclin-dependent kinase inhibitor $2 \mathrm{~A}$ & 9 p21.3 & 3.01 & 0.24 & 3.25 & 0.0047 \\
\hline 4171 & MCM2 & minichromosome maintenance complex component 2 & $3 q 21.3$ & 2.96 & 0.01 & 2.97 & 0.0008 \\
\hline 995 & $C D C 25 C$ & cell division cycle 25 homolog C & $5 q 31.2$ & 2.87 & -0.01 & 2.87 & 0.0045 \\
\hline 891 & CCNB1 & cyclin B1 & $5 q 13.2$ & 2.82 & -0.06 & 2.76 & 0.0008 \\
\hline 1869 & $E 2 F 1$ & E2F transcription factor 1 & $20 \mathrm{q} 11.22$ & 2.82 & -0.30 & 2.52 & 0.0100 \\
\hline 9700 & ESPL1 & extra spindle pole bodies homolog 1 & $12 q 13.13$ & 2.70 & 0.10 & 2.80 & 0.0007 \\
\hline 8318 & CDC45 & cell division cycle 45 homolog & $22 \mathrm{q} 11.21$ & 2.64 & -0.29 & 2.34 & 0.0027 \\
\hline 8317 & $C D C 7$ & cell division cycle 7 homolog & $1 \mathrm{p} 22.2$ & 2.62 & 0.01 & 2.63 & 0.0006 \\
\hline 4085 & $M A D 2 L 1$ & MAD2 mitotic arrest deficient-like 1 & $4 \mathrm{q} 27$ & 2.61 & -0.19 & 2.42 & 0.0013 \\
\hline 898 & CCNE1 & cyclin E1 & $19 \mathrm{q} 12$ & 2.61 & 0.06 & 2.67 & 0.0041 \\
\hline 1111 & CHEK1 & CHK1 checkpoint homolog & $11 \mathrm{q} 24.2$ & 2.57 & 0.00 & 2.57 & 0.0088 \\
\hline 993 & $C D C 25 A$ & cell division cycle 25 homolog A & $3 p 21.31$ & 2.50 & -0.15 & 2.34 & 0.0044 \\
\hline 9232 & PTTG1 & pituitary tumor-transforming 1 & $5 q 33.3$ & 2.40 & 0.07 & 2.47 & 0.0030 \\
\hline 983 & $C D K 1$ & cyclin-dependent kinase 1 & $10 \mathrm{q} 21.2$ & 2.40 & 0.05 & 2.45 & 0.0058 \\
\hline 10926 & $D B F 4$ & DBF4 homolog & 7q21.12 & 2.22 & 0.06 & 2.28 & 0.0002 \\
\hline 4176 & MCM7 & minichromosome maintenance complex component 7 & $7 q 22.1$ & 2.20 & 0.13 & 2.33 & 0.0002 \\
\hline 890 & CCNA2 & cyclin A2 & $4 q 27$ & 2.17 & 0.03 & 2.20 & 0.0141 \\
\hline 4175 & MCM6 & minichromosome maintenance complex component 6 & $2 q 21.3$ & 2.05 & -0.11 & 1.94 & 0.0002 \\
\hline 6502 & SKP2 & S-phase kinase-associated protein $2(\mathrm{p} 45)$ & $5 \mathrm{p} 13.2$ & 2.04 & 0.23 & 2.27 & 0.0117 \\
\hline 5111 & PCNA & proliferating cell nuclear antigen & $20 \mathrm{p} 13$ & 2.04 & 0.01 & 2.05 & 0.0017 \\
\hline 5591 & $P R K D C$ & protein kinase, DNA-activated, catalytic polypeptide & $8 \mathrm{q} 11.21$ & 2.01 & -0.03 & 1.98 & 0.0071 \\
\hline 10744 & PTTG2 & pituitary tumor-transforming 2 & $4 \mathrm{p} 14$ & 2.00 & -0.01 & 1.99 & 0.0084 \\
\hline
\end{tabular}
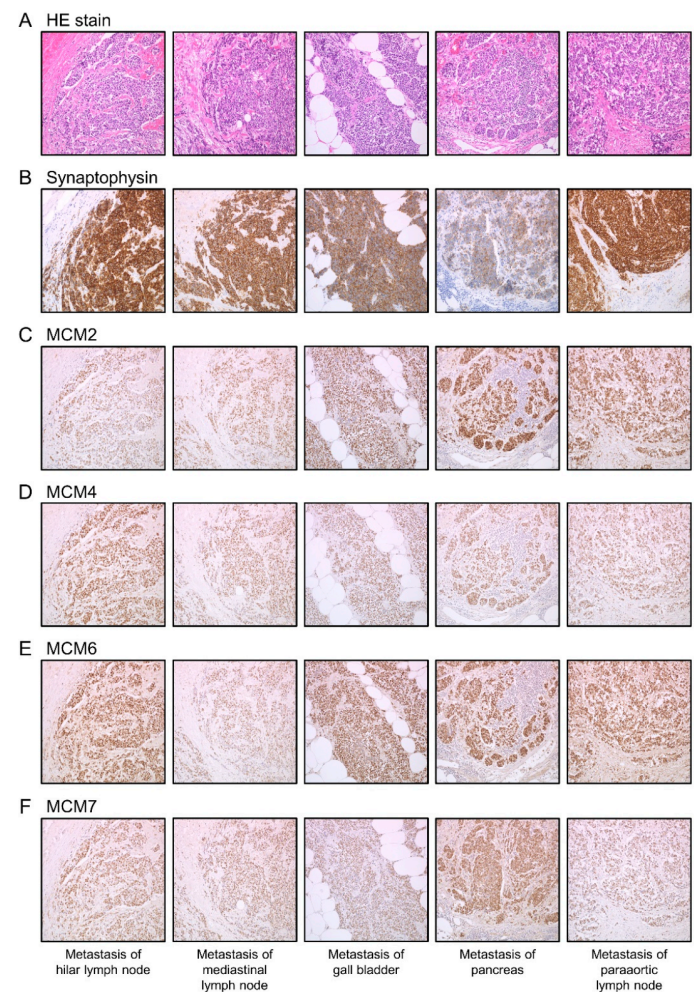

Figure 3. Histopathological findings and immunohistochemical analyses of MCM2, MCM4, MCM6, and MCM7 in case no. 1. Overexpression of (C) MCM2, (D) MCM4, (E) MCM6, and (F) MCM7 was observed in the nuclei of cancer cells at the same location as the tumor sites of (A) HE stain and the high expression sites of (B) Synaptophysin. Micrographs were taken at 200× magnification. 


\subsection{Effect of MCM2, MCM4, MCM6 and MCM7 Knockdown on SCLC Cells}

To identify the functions of MCM2, MCM4, MCM6, and MCM7, we performed siRNAmediated knockdown assays in SBC-3 and H82 cells. RT-PCR and Western blotting showed that expression levels of both mRNA and protein were markedly reduced by both siRNAs (Figure S5). Cell proliferation assays showed the reduced growth of SCLC cells transfected with siRNAs targeting $M C M 2, M C M 4, M C M 6$, or MCM7 compared with those transfected with the control siRNA (Figure 4).
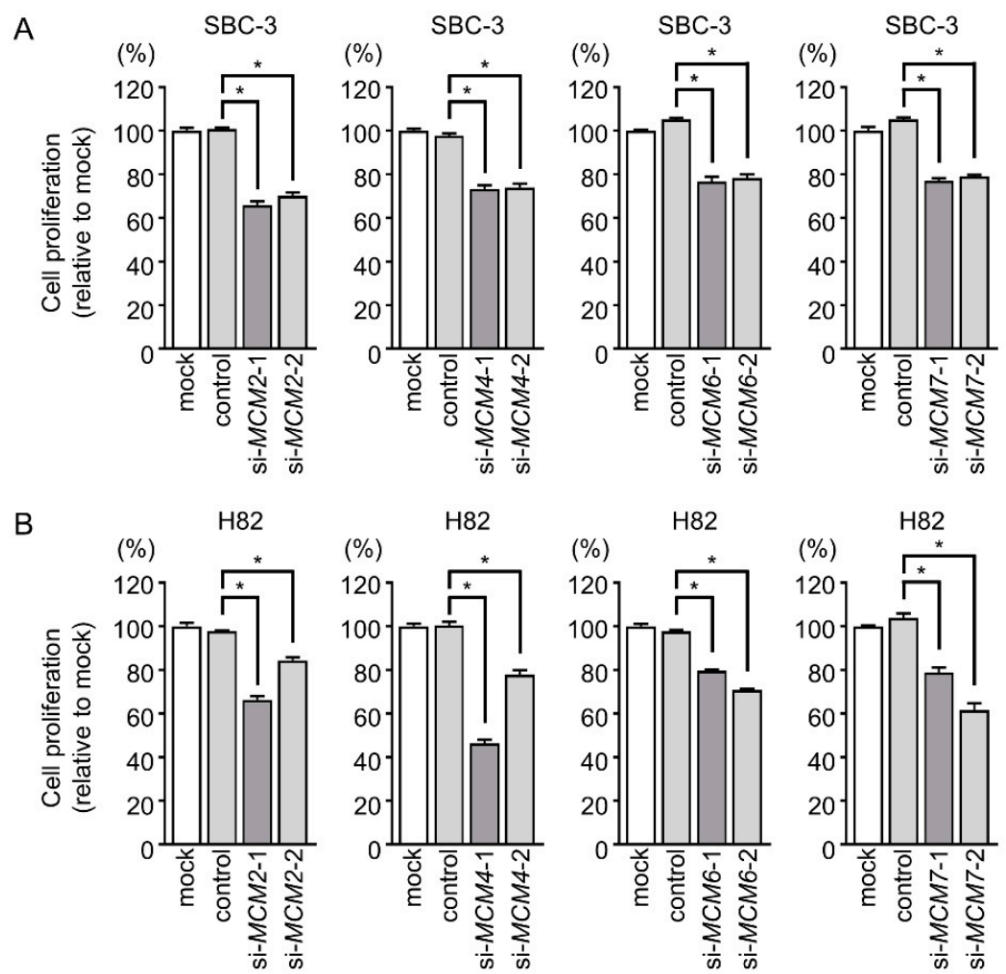

Figure 4. Effect of siRNA-mediated knockdown of MCM family members on the proliferation of SCLC cells. (A,B) Cell proliferation was evaluated by XTT assay. Cell proliferation was suppressed by transfection of siRNAs targeting MCM2, MCM4, MCM6, or MCM7 in SBC-3 and H82 cells. $*, p<0.0001$.

We also performed cell cycle and apoptosis assays. The cell cycle assay demonstrated an increased proportion of cells in the G0/G1 phase after knockdown using si-MCM2-1 and si-MCM4-1 and an increased proportion of cells in the G2/M phase after knockdown using si-MCM6-1 and si-MCM7-1 in both SCLC cell lines (Figure 5). Also, in SBC-3 cells, si-MCM6-2 and si-MCM7-2 transfected cells increased proportion of cells in the G2/M phase, while in H82 cells, si-MCM6-2 and si-MCM7-2 transfected cells increased proportion of cells in the G0/G1 phase.

In the apoptosis assay, $M C M 4, M C M 6$, or $M C M 7$ knockdown increased the percentage of apoptotic cells in both SCLC cell lines (Figure 6 and Figure S6). 
A
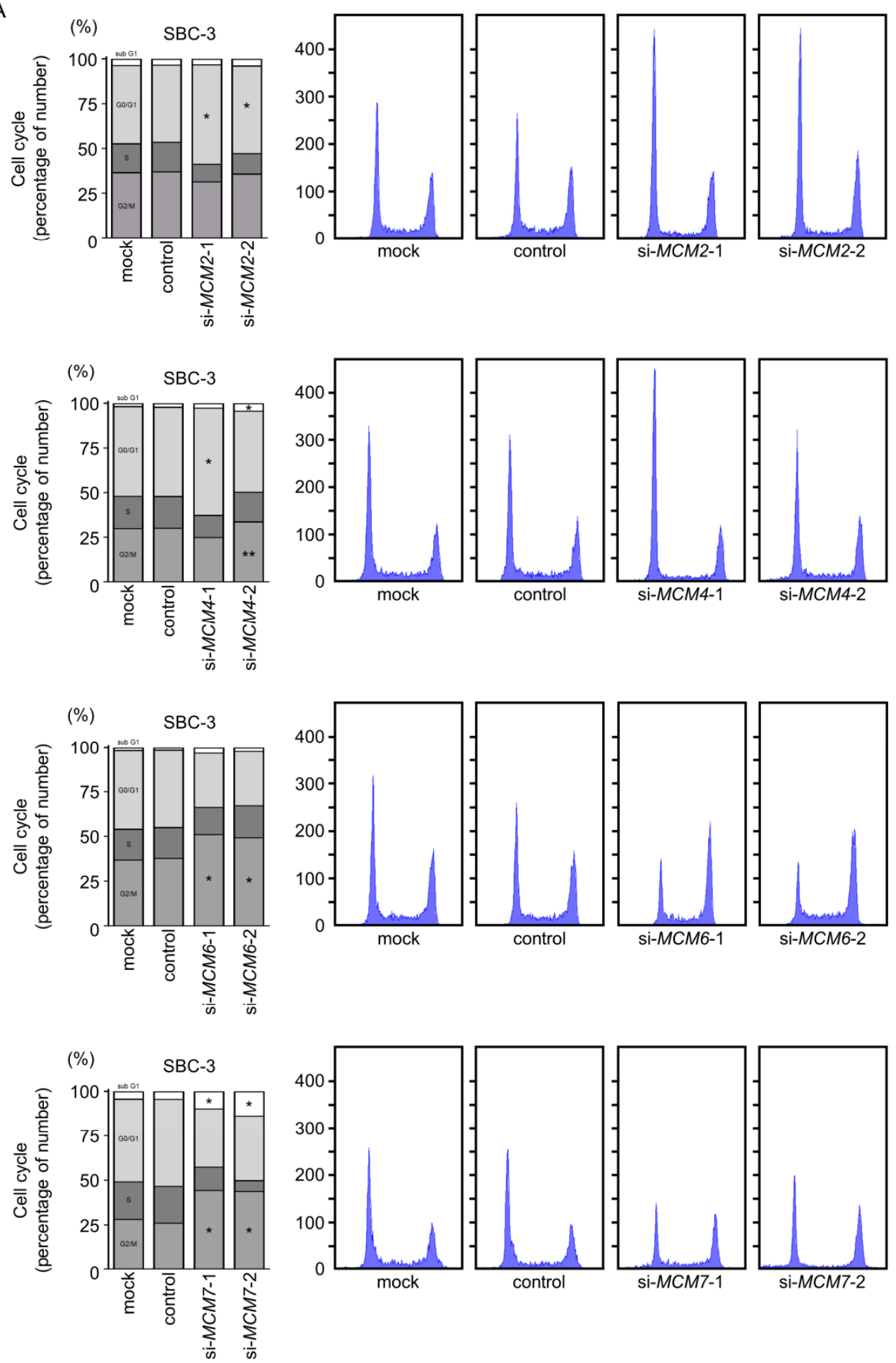

Figure 5. Cont. 
B
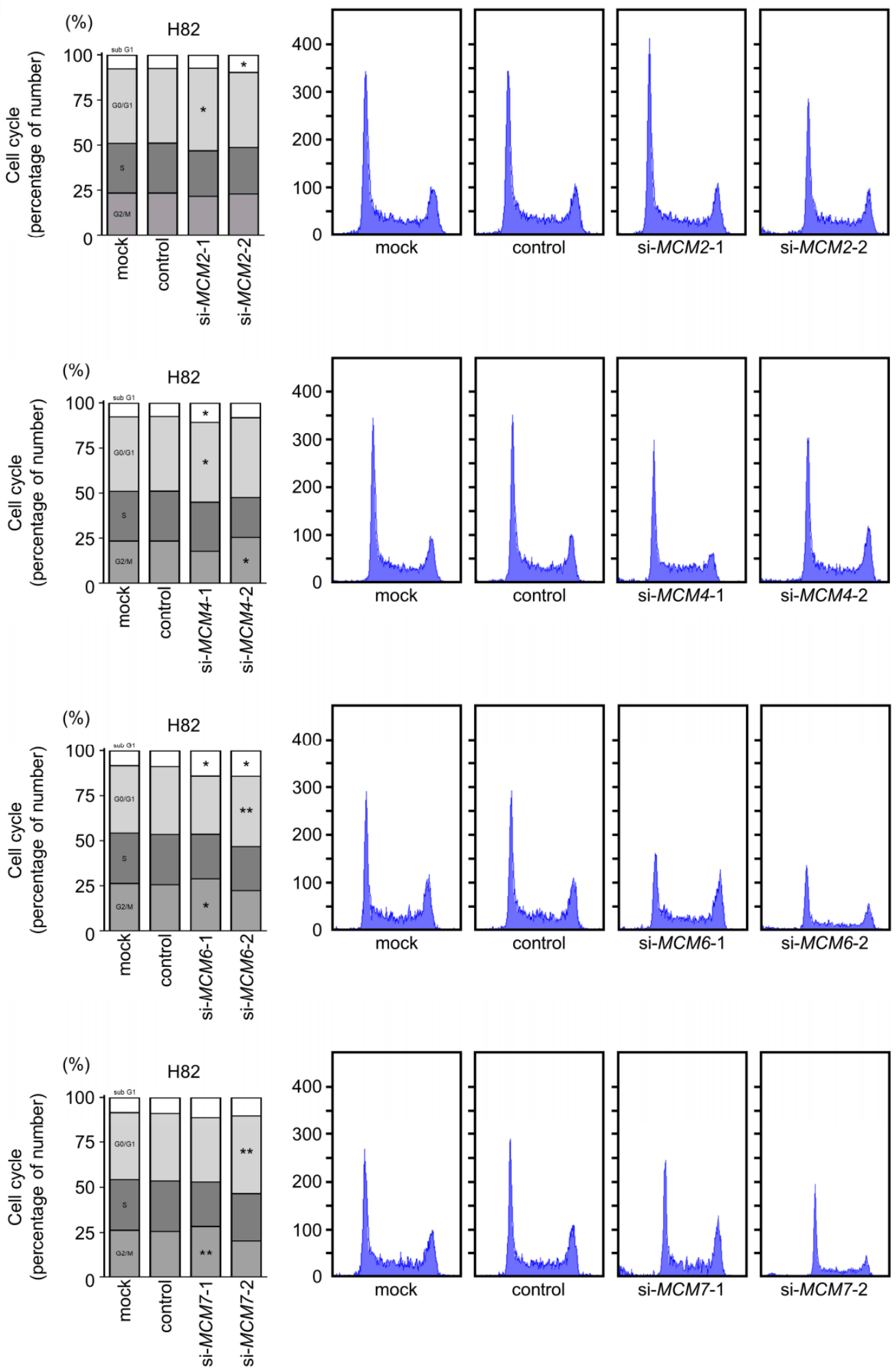

Figure 5. Effect of siRNA-mediated knockdown of MCM family members on cell cycle regulation in SCLC cells. (A) In SBC-3 cells, the cell cycle assay indicated G0/G1 phase arrest in cells transfected with siRNAs targeting MCM2 or MCM4 and G2/M phase arrest in cells transfected with siRNAs targeting MCM6 and MCM7. (B) In H82 cells, si-MCM2-1 or si-MCM4-1 transfected cells increased proportion of cells in the G0/G1 phase and si-MCM6-1 or si-MCM7-1 transfected cells increased proportion of cells in the G2/M phase. Also, the number of cells in the G0/G1 phase were significantly elevated in si-MCM6-2 and si-MCM7-2 transfected cells compared with control cells. ${ }^{*}, p<0.0001$, **, $p<0.01$. 
A
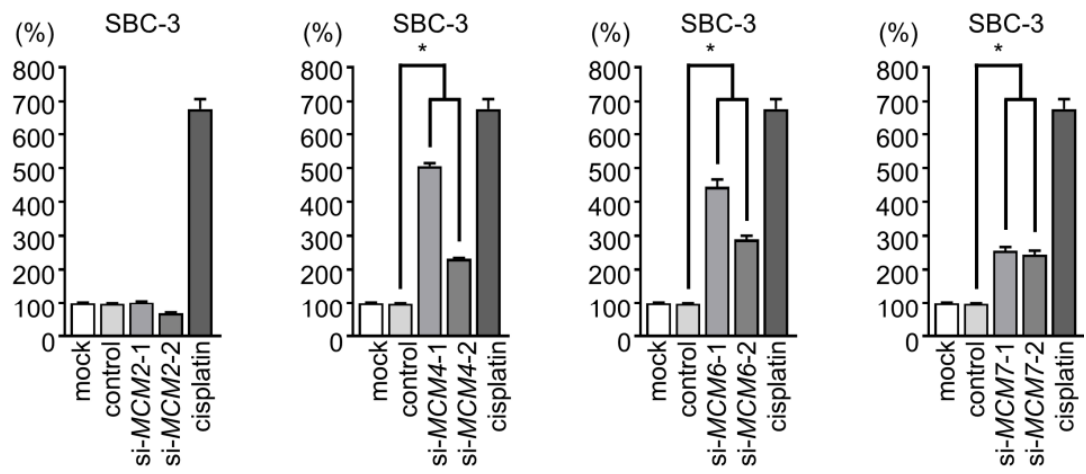

B
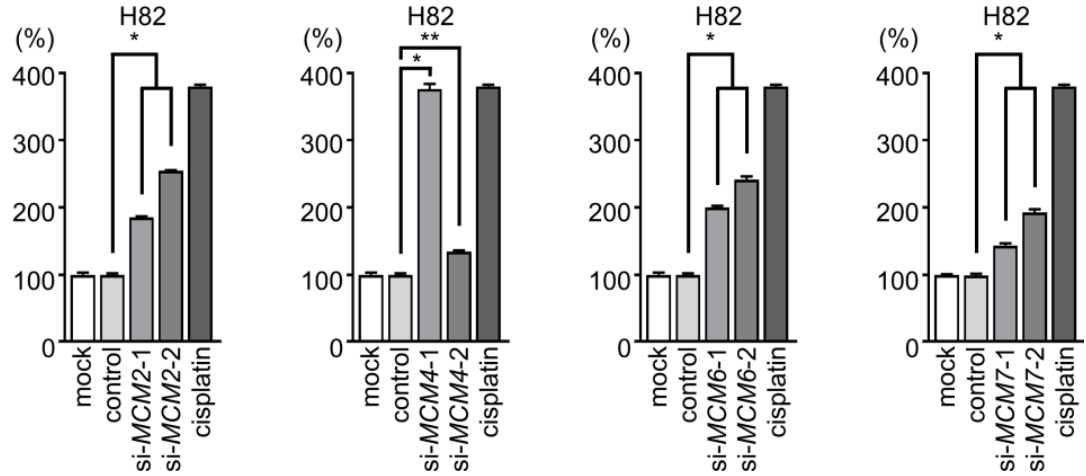

Figure 6. Effect of siRNA-mediated knockdown of MCM family members on apoptosis in SCLC cells. In both SBC-3 and H82 cells, the number of apoptotic cells was increased by transfection of siRNAs targeting MCM4, MCM6, or MCM7. Transfection of the MCM2-specific siRNAs caused apoptosis only in H82 cells. ${ }^{*}, p<0.0001,{ }^{* *}, p<0.01$.

\subsection{Enhanced Cisplatin Sensitivity by Knockdown of MCM Family Members in SBC-3 Cells}

To detect the effect of MCM2, MCM4, MCM6, or MCM7 knockdown on cisplatin sensitivity, SBC-3 cells were treated with cisplatin only or cisplatin together with siRNAs targeting each MCM member. Cell viability was then assessed by XTT assay. All siRNAs significantly reduced the $\mathrm{IC}_{50}$ of cisplatin, suggesting increased sensitivity of SCLC cells to cisplatin after MCM knockdown (Figure 7).

A

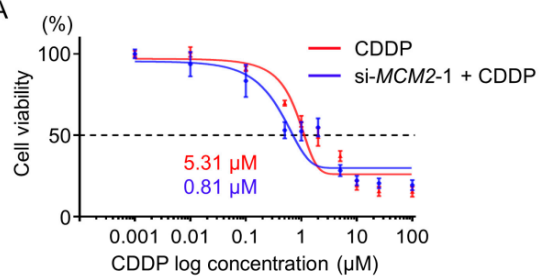

C

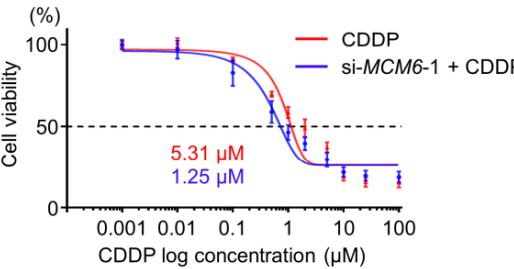

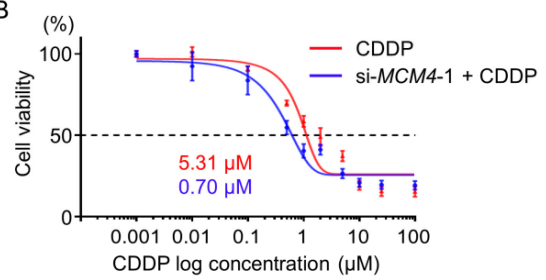

$\mathrm{D}$

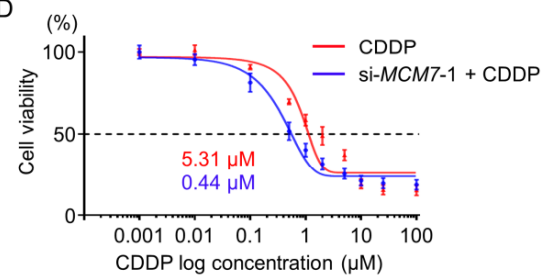

Figure 7. Effect of siRNA-mediated knockdown of MCM family members on cisplatin sensitivity. (A-D) The $\mathrm{IC}_{50}$ values of cisplatin in SBC-3 cells treated with cisplatin and siRNAs targeting each $M C M$ gene for $72 \mathrm{~h}$ were determined by XTT assay. The knockdown of MCM2, MCM4, MCM6 and MCM7 increased the toxicity of cisplatin to SBC-3 cells. 


\section{Discussion}

Due to the rapid progression and quite invasive nature, approximately $70 \%$ of SCLC patients are advanced stage at the time of initial diagnosis [3]. Platinum-based chemotherapy is the first-line treatment for patients with ED-SCLC [4,7]. SCLC cells respond to this treatment initially, but over the course of treatment, they acquire resistance to treatment, and most patients relapse. The prognosis of patients with relapse is less than 1 year [7]. In order to control cancer cells that have acquired treatment resistance, genome analysis research using specimens of patients who have become treatment resistant is indispensable. We have succeeded in creating a molecular signature using clinical specimens of SCLC patients with treatment failure. Although the number of cases is limited, it provides a valuable signature that has been rarely reported so far.

Large-scale analyses using clinical specimens have been scarce because many patients with SCLC are not indicated for surgery. Regardless, several studies have sought to elucidate the malignant features of SCLC cells. Based on the available gene expression data so far, bioinformatics analysis has revealed the genes and molecular pathways involved in SCLC malignant transformation [10-12]. Taking the previous reports together, several genes are highly expressed in cancer cells and integrally involved in SCLC pathogenesis, including NDC80, BUB1B, KIF2C, CDC20, MAD2L1, TOP2A, PCNA, RFC4, CHEK1, TYMS, MCM2, CDKN3, MCM3, CDC6, KIF11, MSH2, and RAD21 [12].

Our present study based on KEGG pathway analysis showed that the genes upregulated in SCLC tissues were associated with the "cell cycle", "Fanconi anemia", "alcoholism", "systemic lupus erythematosus", "oocyte meiosis", "homologous recombination", "DNA replication", and "p53 signaling" pathways. Notably, a previous study of differentially gene expression analysis of SCLC by using GEO datasets (GSE6044 and GSE11969) showed that DNA replication pathway including MCM-family was upregulated in SCLC patients [26]. These analyzes were SCLC specimens that have not been treated with anticancer drugs. These results strongly suggest that DNA replication pathway involved genes are therapeutic targets for SCLC. We focused on MCM family genes (MCM2, MCM4, MCM6, and MCM7), which were identified as having roles in the "cell cycle" and "DNA replication" pathways. Cancer cells exhibit dysregulation of the cell cycle, leading to uncontrollable cell proliferation. Therefore, aberrantly expressed genes involved in the cell cycle and DNA replication are potential therapeutic targets. The replisome is a complex molecular machinery that closely contributes to DNA replication. Notably, some of the genes that make up replisome were upregulated in treatment failure patients with SCLC, e.g., cell division cycle 7 (CDC7), cell division cycle 45 (CDC45), MCM2, MCM4, MCM6, and MCM7. Control of replisome is an important concept in cancer treatment. The MCM complex is a eukaryotic replicative helicase that functions as a molecular motor unwinding duplex DNA to generate single strands of DNA templates for replication [21]. The MCM family contains six proteins (MCM2-7), which form a heterohexameric complex [21]. Several kinases phosphorylate the MCM complex, leading to the recruitment of CDC45 and GINS family members and formation of replisomes, essential DNA replication units [27]. It has been reported that the MCM complex comprising MCM2-7 has various functions other than replication (e.g., transcription, replication checkpoint, and RNA splicing) depending on the phosphorylation sites and status [27-30].

In cancer cells, the aberrant expression of MCM family members has been reported in a wide range of cancers, and cancer cell malignant phenotypes can be suppressed by knockdown of these genes [31-34]. Our recent study showed that siRNA-mediated knockdown of MCM4 attenuated the aggressiveness of lung adenocarcinoma cells [22]. In this study, siRNA-mediated knockdown of MCM2, MCM4, MCM6, and MCM7 enhanced the cisplatin sensitivity of SCLC cells. Proteins of the replisome complex, including MCM proteins, are target molecules for SCLC treatment.

Ciprofloxacin is a broad-spectrum antibiotic that binds to DNA gyrases and exhibits antibacterial activity by inhibiting DNA replication. A previous study showed that ciprofloxacin at low concentrations blocked the DNA helicase activity of the MCM 
complex [35]. Based on high-throughput screening of 2 million compounds, AS4583 was found to inhibit the cell proliferation and DNA replication of cancer cells via the disruption of the MCM complex, especially MCM2 [36]. Moreover, a structure-activity relationship study of AS4583 led to the discovery of RJ-LC-07-48, which is a more effective anticancer drug for treating lung cancer cells resistant to tyrosine kinase inhibitors [36]. Our expression signature revealed that cell division cycle $7(C D C 7)$ was overexpressed in SCLC tissues after treatment failure. CDC7 is a crucial kinase required for initiating the replication machinery [37], and its overexpression has been reported in various cancers [37-39]. Importantly, CDC7 phosphorylates the MCM complex to activate its helicase function [39-41]. In melanoma cells, a sustained CDC7 expression and associated MCM2-7 activation were observed in vemurafenib-resistant cells, and the CDC7 inhibitor TAK-931 was suggested as a therapeutic option for vemurafenib-resistant melanoma cells [39]. CDC7 overexpression and constitutive MCM2-7 activation might contribute to the molecular pathogenesis of drug resistance in SCLC cells. The development of drugs that control CDC7 and MCM-family activation may contribute to the treatment of SCLC patients.

In this study, we created a molecular signature of patients with SCLC who became treatment failure. This signature contains a number of molecules that may control treatment resistance. Based on this signature, the understanding of molecular pathogenesis for treatment-resistant SCLC will be accelerated.

\section{Conclusions}

In conclusion, we successfully identified an expression signature of SCLC after treatment failure using clinical specimens. Among the genes upregulated in SCLC tissues compared with normal tissues, "cell cycle" and "DNA replication" were identified as enriched pathways. DNA replisome-related genes, MCM2, MCM4, MCM6, MCM7, CDC45, and $C D C 7$, were identified as upregulated in the SCLC tissues and may be potential therapeutic targets for treatment-resistant SCLC cells. The treatment-failure signature for SCLC derived from this study will contribute to elucidating the molecular pathogenesis of cancer cells that have acquired treatment resistance.

Supplementary Materials: The following are available online at https: / www.mdpi.com/2072-6 694/13/6/1187/s1, Figure S1: Flowchart of the genes upregulated in SCLC compared with normal tissues classified by KEGG pathway analysis, Figure S2: Histopathological findings and immunohistochemical analyses of MCM2, MCM4, MCM6, and MCM7 in case no. 2, Figure S3: Histopathological findings and immunohistochemical analyses of MCM2, MCM4, MCM6, and MCM7 in case no. 3, Figure S4: Histopathological findings and immunohistochemical analyses of MCM2, MCM4, MCM6, and MCM7 in normal lung tissue, Figure S5: Downregulation of MCM family members by siRNA transfection in SCLC cells, Figure S6: Apoptosis data obtained by flow cytometry from H82 and SBC-3 cells transfected with siRNAs targeting MCM2, MCM4, MCM6, and MCM7, Table S1: Reagents used in this study, Table S2: Upregulated genes associated with Homologous recombination pathway, Table S3: Upregulated genes associated with DNA replication pathway, Table S4: Upregulated genes associated with p53 signaling pathway.

Author Contributions: Conceptualization, H.I., N.S. and K.M.; methodology, N.N., K.M. and N.S.; validation, A.U., H.S. and T.S.; investigation, S.M. (Shunsuke Misono), K.M., K.T., A.U., H.S., R.O. and S.M. (Shogo Moriya); resources, T.S. and H.I.; writing (original draft preparation), S.M. (Shunsuke Misono), K.M. and N.S.; writing (review and editing), N.N. and H.I.; visualization, S.M. (Shunsuke Misono), T.S., K.T. and K.M.; supervision, N.S.; funding acquisition, S.M. (Shunsuke Misono), K.M., H.S., A.U. and N.S. All authors have read and agreed to the published version of the manuscript.

Funding: The present study was supported by KAKENHI grants 18K09338, 19K08627, 19K08656, and 19K17640.

Institutional Review Board Statement: The study was conducted according to the guidelines of the Declaration of Helsinki, and approved by Ethics Committee of Kagoshima University (protocol code: 26-164, date of approval: 10 February 2017). 
Informed Consent Statement: Informed consent was obtained from all subjects involved in the study.

Data Availability Statement: Data is contained within the article or supplementary material.

Conflicts of Interest: The authors declare no conflict of interest. N.N. is an employee of MSD K.K., a subsidiary of Merck \& Co., Inc., and reports personal fees from MSD K.K. outside of this study.

\section{References}

1. Bray, F.; Ferlay, J.; Soerjomataram, I.; Siegel, R.L.; Torre, L.A.; Jemal, A. Global cancer statistics 2018: GLOBOCAN estimates of incidence and mortality worldwide for 36 cancers in 185 countries. CA Cancer J. Clin. 2018, 68, 394-424. [CrossRef] [PubMed]

2. Travis, W.D.; Brambilla, E.; Nicholson, A.G.; Yatabe, Y.; Austin, J.H.M.; Beasley, M.B.; Chirieac, L.R.; Dacic, S.; Duhig, E.; Flieder, D.B.; et al. The 2015 World Health Organization Classification of Lung Tumors: Impact of Genetic, Clinical and Radiologic Advances Since the 2004 Classification. J. Thorac. Oncol. 2015, 10, 1243-1260. [CrossRef] [PubMed]

3. Calles, A.; Aguado, G.; Sandoval, C.; Álvarez, R. The role of immunotherapy in small cell lung cancer. Clin. Transl. Oncol. 2019, 21, 961-976. [CrossRef] [PubMed]

4. Tsiouprou, I.; Zaharias, A.; Spyratos, D. The Role of Immunotherapy in Extensive Stage Small-Cell Lung Cancer: A Review of the Literature. Can. Respir. J. 2019, 2019, 6860432. [CrossRef]

5. Ito, T.; Kudoh, S.; Ichimura, T.; Fujino, K.; Hassan, W.A.; Udaka, N. Small cell lung cancer, an epithelial to mesenchymal transition (EMT)-like cancer: Significance of inactive Notch signaling and expression of achaete-scute complex homologue 1. Hum. Cell 2017, 30, 1-10. [CrossRef]

6. Yang, S.; Zhang, Z.; Wang, Q. Emerging therapies for small cell lung cancer. J. Hematol. Oncol. 2019, 12, 47. [CrossRef]

7. Farago, A.F.; Keane, F.K. Current standards for clinical management of small cell lung cancer. Transl. Lung Cancer Res. 2018, 7 , 69-79. [CrossRef]

8. Arroyo, M.; Larrosa, R.; Gómez-Maldonado, J.; Cobo, M.; Claros, M.G.; Bautista, R. Expression-based, consistent biomarkers for prognosis and diagnosis in lung cancer. Clin. Transl. Oncol. 2020, 22, 1867-1874. [CrossRef]

9. Fujii, K.; Miyata, Y.; Takahashi, I.; Koizumi, H.; Saji, H.; Hoshikawa, M.; Takagi, M.; Nishimura, T.; Nakamura, H. Differential Proteomic Analysis between Small Cell Lung Carcinoma (SCLC) and Pulmonary Carcinoid Tumors Reveals Molecular Signatures for Malignancy in Lung Cancer. Proteom. Clin. Appl. 2018, 12, e1800015. [CrossRef]

10. Liao, Y.; Yin, G.; Wang, X.; Zhong, P.; Fan, X.; Huang, C. Identification of candidate genes associated with the pathogenesis of small cell lung cancer via integrated bioinformatics analysis. Oncol. Lett. 2019, 18, 3723-3733. [CrossRef]

11. Li, X.; Ma, C.; Luo, H.; Zhang, J.; Wang, J.; Guo, H. Identification of the differential expression of genes and upstream microRNAs in small cell lung cancer compared with normal lung based on bioinformatics analysis. Medicine 2020, 99, e19086. [CrossRef] [PubMed]

12. Mao, Y.; Xue, P.; Li, L.; Xu, P.; Cai, Y.; Chu, X.; Jiang, P.; Zhu, S. Bioinformatics analysis of mRNA and miRNA microarray to identify the key miRNA-gene pairs in small-cell lung cancer. Mol. Med. Rep. 2019, 20, 2199-2208. [CrossRef]

13. Peifer, M.; Fernández-Cuesta, L.; Sos, M.L.; George, J.; Seidel, D.; Kasper, L.H.; Plenker, D.; Leenders, F.; Sun, R.; Zander, T.; et al. Integrative genome analyses identify key somatic driver mutations of small-cell lung cancer. Nat. Genet. 2012, 44, 1104-1110. [CrossRef]

14. Rudin, C.M.; Durinck, S.; Stawiski, E.W.; Poirier, J.T.; Modrusan, Z.; Shames, D.S.; Bergbower, E.A.; Guan, Y.; Shin, J.; Guillory, J.; et al. Comprehensive genomic analysis identifies SOX2 as a frequently amplified gene in small-cell lung cancer. Nat. Genet. 2012, 44, 1111-1116. [CrossRef]

15. Umemura, S.; Mimaki, S.; Makinoshima, H.; Tada, S.; Ishii, G.; Ohmatsu, H.; Niho, S.; Yoh, K.; Matsumoto, S.; Takahashi, A.; et al. Therapeutic priority of the PI3K/AKT/mTOR pathway in small cell lung cancers as revealed by a comprehensive genomic analysis. J. Thorac. Oncol. 2014, 9, 1324-1331. [CrossRef]

16. George, J.; Lim, J.S.; Jang, S.J.; Cun, Y.; Ozretić, L.; Kong, G.; Leenders, F.; Lu, X.; Fernández-Cuesta, L.; Bosco, G.; et al. Comprehensive genomic profiles of small cell lung cancer. Nature 2015, 524, 47-53. [CrossRef] [PubMed]

17. Dowlati, A.; Lipka, M.B.; McColl, K.; Dabir, S.; Behtaj, M.; Kresak, A.; Miron, A.; Yang, M.; Sharma, N.; Fu, P.; et al. Clinical correlation of extensive-stage small-cell lung cancer genomics. Ann. Oncol. 2016, 27, 642-647. [CrossRef] [PubMed]

18. Udagawa, H.; Umemura, S.; Murakami, I.; Mimaki, S.; Makinoshima, H.; Ishii, G.; Miyoshi, T.; Kirita, K.; Matsumoto, S.; Yoh, K.; et al. Genetic profiling-based prognostic prediction of patients with advanced small-cell lung cancer in large scale analysis. Lung Cancer 2018, 126, 182-188. [CrossRef]

19. Sundaresan, V.; Lin, V.T.; Liang, F.; Kaye, F.J; Kawabata-Iwakawa, R.; Shiraishi, K.; Kohno, T.; Yokota, J.; Zhou, L. Significantly mutated genes and regulatory pathways in SCLC-a meta-analysis. Cancer Genet. 2017, 216-217, 20-28. [CrossRef]

20. Pleasance, E.D.; Stephens, P.J.; O’Meara, S.; McBride, D.J.; Meynert, A.; Jones, D.; Lin, M.L.; Beare, D.; Lau, K.W.; Greenman, C.; et al. A small-cell lung cancer genome with complex signatures of tobacco exposure. Nature 2010, 463, 184-190. [CrossRef]

21. Bochman, M.L.; Schwacha, A. The Mcm complex: Unwinding the mechanism of a replicative helicase. Microbiol. Mol. Biol. Rev. 2009, 73, 652-683. [CrossRef] 
22. Sanada, H.; Seki, N.; Mizuno, K.; Misono, S.; Uchida, A.; Yamada, Y.; Moriya, S.; Kikkawa, N.; Machida, K.; Kumamoto, T.; et al. Involvement of Dual Strands of miR-143 (miR-143-5p and miR-143-3p) and Their Target Oncogenes in the Molecular Pathogenesis of Lung Adenocarcinoma. Int. J. Mol. Sci. 2019, 20, 4482. [CrossRef]

23. Misono, S.; Seki, N.; Mizuno, K.; Yamada, Y.; Uchida, A.; Sanada, H.; Moriya, S.; Kikkawa, N.; Kumamoto, T.; Suetsugu, T.; et al. Molecular Pathogenesis of Gene Regulation by the miR-150 Duplex: miR-150-3p Regulates TNS4 in Lung Adenocarcinoma. Cancers 2019, 11, 601. [CrossRef] [PubMed]

24. Uchida, A.; Seki, N.; Mizuno, K.; Yamada, Y.; Misono, S.; Sanada, H.; Kikkawa, N.; Kumamoto, T.; Suetsugu, T.; Inoue, H. Regulation of KIF2A by Antitumor miR-451a Inhibits Cancer Cell Aggressiveness Features in Lung Squamous Cell Carcinoma. Cancers 2019, 11, 258. [CrossRef]

25. Mizuno, K.; Tanigawa, K.; Nohata, N.; Misono, S.; Okada, R.; Asai, S.; Moriya, S.; Suetsugu, T.; Inoue, H.; Seki, N. FAM64A: A Novel Oncogenic Target of Lung Adenocarcinoma Regulated by Both Strands of miR-99a (miR-99a-5p and miR-99a-3p). Cells 2020, 9, 2083. [CrossRef]

26. Wen, P.; Chidanguro, T.; Shi, Z.; Gu, H.; Wang, N.; Wang, T.; Li, Y.; Gao, J. Identification of candidate biomarkers and pathways associated with SCLC by bioinformatics analysis. Mol. Med. Rep. 2018, 18, 1538-1550. [CrossRef]

27. Fei, L.; Xu, H. Role of MCM2-7 protein phosphorylation in human cancer cells. Cell Biosci. 2018, 8, 43. [CrossRef]

28. Snyder, M.; Huang, X.Y.; Zhang, J.J. The minichromosome maintenance proteins 2-7 (MCM2-7) are necessary for RNA polymerase II (Pol II)-mediated transcription. J. Biol. Chem. 2009, 284, 13466-13472. [CrossRef] [PubMed]

29. Chen, Z.H.; Yu, Y.P.; Michalopoulos, G.; Nelson, J.; Luo, J.H. The DNA replication licensing factor miniature chromosome maintenance 7 is essential for RNA splicing of epidermal growth factor receptor, c-Met, and platelet-derived growth factor receptor. J. Biol. Chem. 2015, 290, 1404-1411. [CrossRef] [PubMed]

30. Stead, B.E.; Brandl, C.J.; Sandre, M.K.; Davey, M.J. Mcm2 phosphorylation and the response to replicative stress. BMC Genet. 2012, 13, 36. [CrossRef] [PubMed]

31. Lau, K.M.; Chan, Q.K.; Pang, J.C.; Li, K.K.; Yeung, W.W.; Chung, N.Y.; Lui, P.C.; Tam, Y.S.; Li, H.M.; Zhou, L.; et al. Minichromosome maintenance proteins 2, 3 and 7 in medulloblastoma: Overexpression and involvement in regulation of cell migration and invasion. Oncogene 2010, 29, 5475-5489. [CrossRef] [PubMed]

32. Zhang, X.; Teng, Y.; Yang, F.; Wang, M.; Hong, X.; Ye, L.G.; Gao, Y.N.; Chen, G.Y. MCM2 is a therapeutic target of lovastatin in human non-small cell lung carcinomas. Oncol. Rep. 2015, 33, 2599-2605. [CrossRef] [PubMed]

33. Qiu, Y.T.; Wang, W.J.; Zhang, B.; Mei, L.L.; Shi, Z.Z. MCM7 amplification and overexpression promote cell proliferation, colony formation and migration in esophageal squamous cell carcinoma by activating the AKT1/mTOR signaling pathway. Oncol. Rep. 2017, 37, 3590-3596. [CrossRef]

34. Yu, S.; Wang, G.; Shi, Y.; Xu, H.; Zheng, Y.; Chen, Y. MCMs in Cancer: Prognostic Potential and Mechanisms. Anal. Cell. Pathol. 2020, 2020, 3750294. [CrossRef]

35. Simon, N.; Bochman, M.L.; Seguin, S.; Brodsky, J.L.; Seibel, W.L.; Schwacha, A. Ciprofloxacin is an inhibitor of the Mcm2-7 replicative helicase. Biosci. Rep. 2013, 33. [CrossRef]

36. Lin, C.Y.; Wu, H.Y.; Hsu, Y.L.; Cheng, T.R.; Liu, J.H.; Huang, R.J.; Hsiao, T.H.; Wang, C.J.; Hung, P.F.; Lan, A.; et al. Suppression of Drug-Resistant Non-Small-Cell Lung Cancer with Inhibitors Targeting Minichromosomal Maintenance Protein. J. Med. Chem. 2020, 63, 3172-3187. [CrossRef]

37. Montagnoli, A.; Moll, J.; Colotta, F. Targeting cell division cycle 7 kinase: A new approach for cancer therapy. Clin. Cancer Res. 2010, 16, 4503-4508. [CrossRef]

38. Cao, J.X.; Lu, Y. Targeting CDC7 improves sensitivity to chemotherapy of esophageal squamous cell carcinoma. OncoTargets Ther. 2019, 12, 63-74. [CrossRef] [PubMed]

39. Gad, S.A.; Ali, H.E.A.; Gaballa, R.; Abdelsalam, R.M.; Zerfaoui, M.; Ali, H.I.; Salama, S.H.; Kenawy, S.A.; Kandil, E.; Abd Elmageed, Z.Y. Targeting CDC7 sensitizes resistance melanoma cells to BRAF(V600E)-specific inhibitor by blocking the CDC7/MCM2-7 pathway. Sci. Rep. 2019, 9, 14197. [CrossRef] [PubMed]

40. Masai, H.; Matsui, E.; You, Z.; Ishimi, Y.; Tamai, K.; Arai, K. Human Cdc7-related kinase complex. In vitro phosphorylation of MCM by concerted actions of Cdks and Cdc7 and that of a criticial threonine residue of Cdc7 bY Cdks. J. Biol. Chem. 2000, 275, 29042-29052. [CrossRef] [PubMed]

41. Clarke, L.E.; Fountaine, T.J.; Hennessy, J.; Bruggeman, R.D.; Clarke, J.T.; Mauger, D.T.; Helm, K.F. Cdc7 expression in melanomas, Spitz tumors and melanocytic nevi. J. Cutan. Pathol. 2009, 36, 433-438. [CrossRef] [PubMed] 